\title{
Leak in Surgical Safety Checklist?
}

\author{
Franz J Fellacher ${ }^{1}$, Doris Walter ${ }^{2}$, Daniel Aldrian ${ }^{2}$, Franz J Seibert ${ }^{1}$, Renate Krassnig ${ }^{{ }^{*}}$ \\ From Safety in hospitals: from strategy to implementation Annual Scientific Meeting 2015 \\ Graz, Austria. 29-30 September 2015
}

\section{Background}

Since the dawn of surgery patient safety has been a major issue. In 2008 the WHO Surgical Safety Checklist was developed after extensive consultation, aiming to decrease errors and adverse effects. The WHO Checklist is used originally or based on by a majority of surgical providers around the world - even with us. Nevertheless, mistakes happen.

\section{Material and methods}

We report a case that has taken place in our department, supplemented by literature review.

Modified WHO Safety Checklist has been used in our department since a couple of years ago. Although "Team Time Out" was performed standardly following unpleasant situation happened: after an elective arthroscopy, while the surgeon finished documentation, the responsible nurse informed him that the indicator strip for sterility did not show any discoloration.

No one of the operating room personal knew whether the indicator strip was not checked or if it had been overlooked although a modified WHO Surgical Safety Checklist was performed carefully.

Subsequently the question arose, what does it mean to the patient if surgical instruments were not sterilized but only cleaned by Washer-Disinfector.

\section{Results}

The patient has not suffered any infection. Review of the literature has shown that the machine washer-disinfector consistently reduces microorganisms [1]. The risk of transmission of infection may be considered negligible [2].

\section{Conclusion}

Despite the use of checklists, errors still happen. Everyone on the team is required not only to do their own

\footnotetext{
* Correspondence: renate.krassnig@medunigraz.at

${ }^{1}$ Department of Trauma Surgery, Medical University of Graz, Graz, Austria
} Full list of author information is available at the end of the article

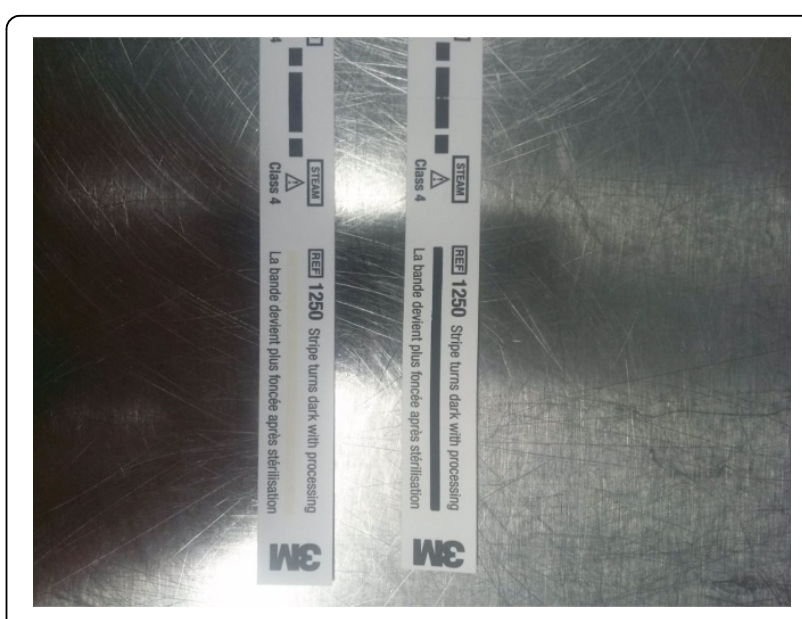

Figure 1 Indicator strip for sterility (black=sterility is given; white=sterility not given).

part. Moreover, everyone is required to take care of "the whole big picture".

\section{Competing interests \\ There are no financial interests to declare.}

\section{Authors' details}

'Department of Trauma Surgery, Medical University of Graz, Graz, Austria. ²Department of General Surgery, University Hospital Graz, Graz, Austria.

Published: 30 October 2015

\section{References}

1. Donskey C, Yowler M, Falck-Ytter Y, Kundrapu S, Saltata RA, Rutala WA: A case study of a real-time evaluation of the risk of disease transmission associated with a failure to follow recommended sterilization procedures. Antimicrob Resist Infect Control 2014, 3(1):4.

2. Rutala WA, Weber DJ: How to assess risk of disease transmission to patients when there is a failure to follow recommended disinfection and sterilization guidelines. Infect Control Hosp Epidemiol 2007, 28(2):146-155.

doi:10.1186/2056-5917-1-S1-A18

Cite this article as: Fellacher et al:: Leak in Surgical Safety Checklist? Safety in Health 2015 1(Suppl 1):A18. 